\title{
Die manifestering van Septuaginta-invloed in die Sondergut-Lukas
}

\author{
GJ Steyn \\ Universiteit van Suid-Afrika
}

\begin{abstract}
The manifestation of Septuagint-influence in the Sondergut-Lukas

It has often been postulated that the Gospel of Luke was influenced by the Septuagint. In a recent study this was proven to be true when research on the language and style of the Gospel was conducted. It manifested a number of similarities between the Septuagint and the Gospel - especially within the source-material peculiar to Luke (Sondergut-Lukas). The childless-motif in Luke 1 and the last part of Jesus' genealogy in Luke 3 are representative examples of this.
\end{abstract}

\section{INLEIDING}

Die vraag na die invloed van die Septuaginta op die taal en styl van die NuweTestamentiese geskrifte het gedurende die huidige eeu steeds meer en meer op die voorgrond begin tree. Swete (1914: 451) het reeds gemeld dat '... the influence ... is continually shown in combinations of words or in trains of thought which point out to the presence of the version in the background of the writer's mind, even when he may not consciously allude to it'.

In die vorige dekade meen Silva (1976: 110) dat hierdie invloed van die Septuaginta op die Nuwe-Testamentiese skrywers een van die weinige gemeenskaplike aannames onder geleerdes is. Hy reken ook dat sodanige invloed primêr te vind is in Lukas-Handelinge en in Openbaring. Ook onder die Suid-Afrikaanse teoloë het Du Plessis (1980: 157) die aandag daarop gevestig dat van al die

- Geldelike bystand gelewer deur die Raad vir (ieesteswetenskaplike Navorsing vir hierdic navorsing word hiermee crken. Menings in hierdie publikasic uitgespreek of gevolgtrekkings waartoc geraak is, is die van die outeur en moet nie aan die Raad vir Geesteswetenskaplike Navorsing toegeskryf word nie. 
Sinoptici, Lukas die meeste deur die Septuaginta beinvloed is.

Ten spyte daarvan dat die feit van Septuaginta-invloed in die Nuwe Testament, en dan hier spesifiek die Lukasevangelie, telkens vermeld word, is daar relatief min aandag in die verlede aan sodanige ondersoek gewy. Enkele werke wat in hierdie verband in 'n beperkte mate moontlik uitgesonder sou kon word, is dié van Cadbury ([1920] 1969), Rese (1965) en Holtz (1968). Nogtans het selfs hierdie werke, ten spyte van hulle groot bydrae tot die Lukas-navorsing, in gebreke gebly om (i) 'n duidelike verteenwoordigende beeld te gee van die voorkoms van Septuagintainvloed op die verskillende taalvlakke van die Lukas Evangelie, en (ii) om die manifestasiepatroon hiervan in die verskillende onderliggende bronne van die Evangelie uit te wys. 'n Poging tot sodanige ondersoek wat beide hierdie fasette akkommodeer, is onlangs van stapel gestuur (vgl Steyn 1987b).

'n Baie interessante feit het in hierdie vermelde ondersoek na vore getree, naamlik dat Septuaginta-invloed in die Lukasevangelie in 'n baie hoër frekwensie by die Sondergut-Lukas aangetref word, as by die res van die Lukasevangelie se bronnemateriaal. Hierdie artikel is 'n kompilasie van twee van die voorbeelde wat as Sondergut-Lukas getipeer word en wat die manifestering van Septuaginta-invloed hierin redelik duidelik behoort te illustreer. Die eerste is die kinderloosheidsmotief in Lukas 1 en die tweede is ' $n$ bespreking rakende die laaste deel van die genealogie van Jesus in Lukas 3.

As doelstelling wil hierdie voorbeelde van die manifestering van Septuagintainvloed in die Lukasevangelie dan eerstens konkrete bewyse daarvan wees dat sodanige invloed wel plaasgevind het. Tweedens wil dit die aandag daarop vestig dat dit in 'n hoër frekwensie by die Sondergut-Lukasmateriaal aangetref word - wat daarop dui dat die (finale) outeur(s) van die Evangelie die Griekse vertaling(s) van die Ou Testament geraadpleeg het in die kompilasie van die Sondergut-Lukas. Derdens wil dit die moontlikheid dat die outeur(s) van skriftelike dokumente van die Septuaginta gebruik gemaak het, suggereer - veral in die lig van die voorbeeld uit die geneaiogie van Lukas 3.

Voordat hierdie twee voorbeeld-eenhede onder bespreking kom, is dit egter nodig om allereers bepaalde terminologieë duideliker te formuleer.

- Wanneer gepraat word van Lukas of die skrywer word dit gebruik as 'n oorkoepelende term om die samesteller(s)/outeur(s) aan te dui wat betrokke was by die kompilasie van die teks soos dit vandag voor ons lê.

* As daar verwys word na die Septuaginta word dit gedoen met inbegrip van die lang en komplekse wordingsproses van hierdie bundel Griekse vertalings (vgl Steyn 1987a: 32-33). 
- Verder moet die aandag ook gevestig word op 'n tekortkoming by hierdie bovermelde ondersoek waaraan daar in die toekoms aandag gegee sal moet word, naamlik die nadere vasstelling van die spesifieke Septuaginta-tradisie (en die Vorlage wat dit verteenwoordig), asook hiermee saam 'n beter benutting van die Göttingen-uitgawe van die Septuaginta wat 'n baie goeie tekskritiese apparaat bevat.

\section{DIE KINDERLOOSHEIDSMOTIEF (LUK 1)}

Net soos in die res van die Nuwe Testament vind ons in Lukas verskillende OuTestamentiese temas, motiewe of idees wat telkens opduik (Marshall 1978: 45). Dit verraai die gebruik van Ou-Testamentiese tradisiemateriaal. Omdat die skrywer nie 'n robot of 'n masjien was nie, maar 'n mens met 'n gedagtesisteem wat hy op skrif probeer vaslê het, word hierdie Ou-Testamentiese tradisiemateriaal nie deur hom slaafs, sistematies en ondermekaar aangebied nie, maar manifesteer dit in die verwerkte interpretasies van sy eie verstaansproses. Die ontleding van hierdie manifestasiepatroon van Ou-Testamentiese materiaal verraai dan ook uiteindelik die skrywer se eie unieke verstaansproses van die Ou Testament.

Die Sondergut-Lukas bevestig baie duidelik hoedanig die Septuaginta, as Griekse Ou Testament, Lukas se denkpatroon beïnvloed het. 'n Goeie snit in hierdie verband word gevind in Lukas 1 waaroor daar nie twyfel bestaan dat dit SondergutLukas-materiaal is nie.

\subsection{Die Abraham-Saramotief (Luk 1: 5-25)}

Opvallend in die voorspelling van die geboorte van Johannes die Doper en Jesus, is die ooreenkomste wat dit vertoon met die verhaal van Abraham en Sara in die Ou Testament (Gen 11-18). Dis baie interessant dat nie net sekere woordvorme identies is met dié in die Septuaginta nie, maar dat dit ook op dieselfde manier en in dieselfde tipe konteks gebruik word.

Ten opsigte van die ooreenstemming tussen Lukas 1: 5-25 en die verhaal van Abraham en Sara in Genesis, het Goulder en Sanderson (1957: 14-15) alreeds op enkele ooreenkomste gewys. 'n Uitbreiding van hierdie aanvoorwerk ontplooi soos volg:

- Net soos Sara onvrugbaar ( $\sigma \tau \epsilon \hat{p} \alpha=$ Gen 11: 30) was, was ook Elisabet onvrug-

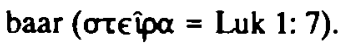




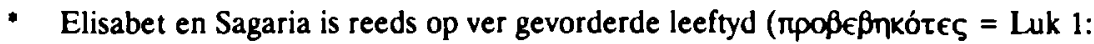
7) wanneer hulle 'n kind gaan hê - net soos die geval was met Abraham en Sara

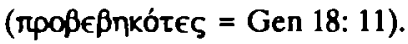

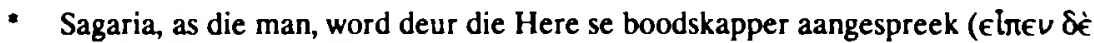

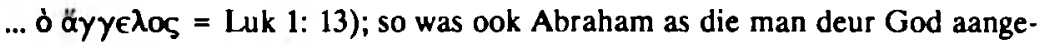
spreek (єirev ... ò Qeòs = Gen 17: 16).

- Die inhoud van Sagaria se boodskap is dat sy vrou aan 'n seun geboorte sal

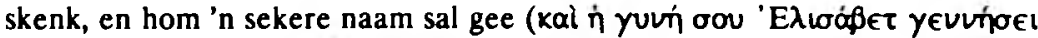

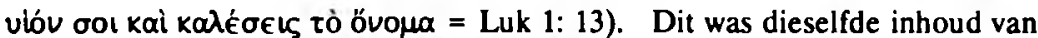

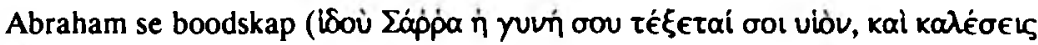

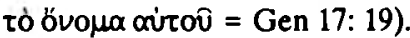

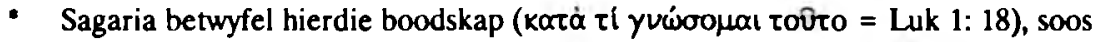

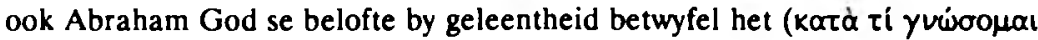
ötı = Gen 15: 8).

- Nadat Sagaria gevra het hoedat hy dit sal weet, gee hy die rede vir sy twyfel

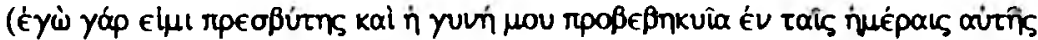
= Luk 1: 18). Dit herinner sterk aan die rede vir Abraham se twyfel ( $\epsilon l \tau \widehat{\varphi}$

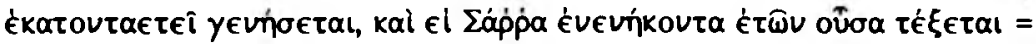
Gen 17: 17).

- Wanneer Gabriël vir Maria vertel van Elisabet se swangerskap, is daar groot

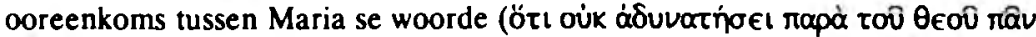

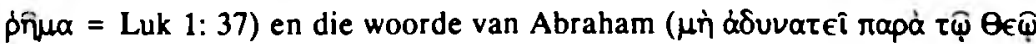
pंกินa = Gen 18: 14).

- Later word Abraham se naam opgeneem in die Magnifical (Luk 1: 55) en die Benedictus (1: 73).

- In die Nunc Dimittis vind sy woorde weer eens weerklank wanneer Sagaria sê: 'Here, laat u dienaar nou in vrede gaan volgens $U$ woord ...' (vîv ómalúels tòv

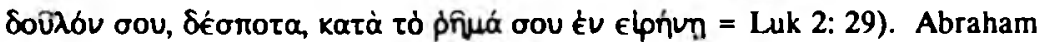

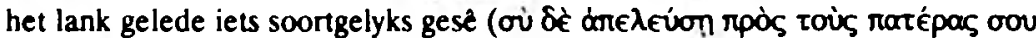

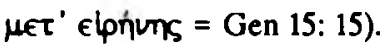


Tog is die Abraham-Saramotief nie die enigste kinderloosheidsmotief wat in Lukas se weergawe weerklank vind nie. 'n Ander ooreenkoms is dié tussen Elisabet en Rebekka, die vrou van Isak.

\subsection{Die Rebekka-motief (Luk 1: 7)}

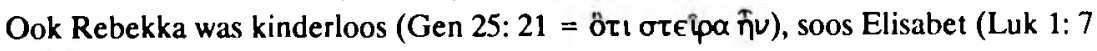

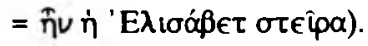

\subsection{Die Ragel-motief (Luk 1: 25)}

Die motief van onvrugbaarheid word ook aan Ragel, die vrou van Jakob, verbind en dan veral in die verband dat haar 'smaad' weggeneem word ('Pax门̀ $\delta \dot{\hat{n}} \hat{\eta} v$

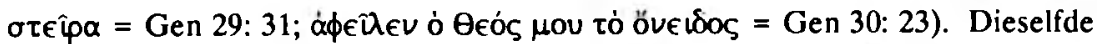

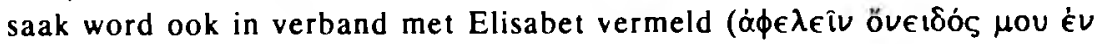

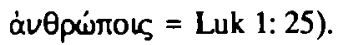

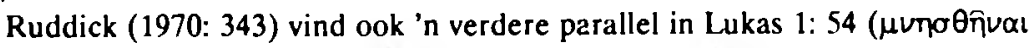

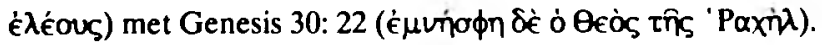

Behalwe hierdie elemente wat uit die aartsvader-(moeder!) -verhale ontleen is, is daar nog ooreenkomste met die verhale van Simson en Samuel.

\subsection{Die Simson-motief (Luk 1: 7, 15)}

Die elemente - kinderloosheid, 'n voorspelling van swangerskap, 'n seun, onthouding van wyn en sterk drank, redding van die volk - word in sowel die Simsonverhaal (Rig 13: 2-5) as Lukas 1 gevind. Vergelyk die volgende ooreenkomste:

- Kinderloosheid (Luk 1: 7 en Rig 13: 3).

- Voorspelling van swangerskap en geboorte van 'n seun (Luk 1: 13, 31 en Rig 13: 3).

- Onthouding van wyn en sterk drank (Luk 1: 15 en Rig 13:4).

- Redder van die volk Israel (Luk 1: 16, 68, 71 en Rig 13: 5).

- 'Van die moederskoot af al afgesonder vir die taak (Luk 1: 15 en Rig 13:5).

- Hulle het gegroei en die 'Gees van die Here het hulle gedryf' (Luk 1: 15, 80 en Rig 13: 24-25).

\subsection{Die Hanna-Samuelmotief (Luk 1: 7, 15, 46-55)}

Behalwe die Magnificat (Luk 1: 46-55) van Maria wat groot ooreenkomste vertoon met die Lofsang van Hanna (1 Kon 2: 1-10 [LXX]), is daar nog die 'wyn en sterk drank' (Luk 1: 15) wat Johannes nie mag drink nie - net soos Samuel (1 Kon 1: 11 [LXX]). 
Let egter ook daarop dat die verbinding olvou - oíkepa in Num 6: 3 en Lev 10: 9 (dit wil sê, in die Tora verteenwoordig) gevind word terwyl die verbinding oivov $\mu e ́ \theta v \sigma \mu \alpha a$ in 1 Kon 1: 11 (LXX) gevind word. (Die Hebreeus-Massoretiese teks van 1 Sam 1: 11 het glad nie hierdie frase nie!)

Tog word die Hanna-Samuel-motief nie net op die geboorteverhaal van Johannes die Doper toegepas nie, maar word dit ook op Maria betrek. By sowel Hanna as Maria word beide deur hulleself beskou as 'n 'dienares' van die Here:

1 Kon $1: 11=\tau$ ก

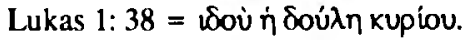

'n Ander duidelike ooreenkoms tussen die verhaal van 1 Kon 1 (LXX) en Lukas 1, is 'n frase wat in die Magnificat voorkom, naamlik Lukas 1: $48=$ ötı éré $\beta \lambda \epsilon \psi \epsilon \nu$ éri

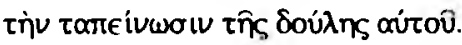

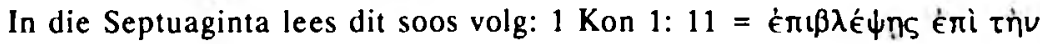

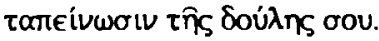

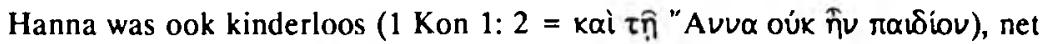

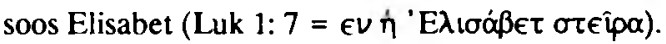

Dit lyk dus moontlik dat Lukas elemente van die Hanna-Samuel motief wat in bogenoemde vyf verhale voorkom, in 'n enkele verhaal oor die geboorte van Johannes die Doper en Jesus verwerk het. By die aartsvaders (Abraham, Isak en Jakob) en hulle vrouens (Sara, Rebekka en Ragel), asook by Simson en Samuel, kon Lukas baie van die elemente vind wat hy nodig gehad het om sy verhaal te komponeer. Sou dit op hierdie wyse wees dat hy 'alles noukeurig' ondersoek en sy verhaal 'na lang ondersoek' saamgestel het?

3. DIE LAASTE DEEL VAN DIE GENEALOGIE VAN JESUS (LUK 3: 34-38 = LXX GEN 11 EN GEN 5)

Uit die laaste helfte van die Lukaanse genealogie word dit duidelik dat Lukas vir die samestelling hiervan, van die volgende bronne gebruik kon gemaak het: eerstens dieselfde bron(ne) as Matteus ( $Q$ ?) vir die deel van 3: 31e-34c, tweedens van Genesis 11: 10-32 vir die deel van 3: 34d-36c, en laastens van Genesis 5: 1-32 vir 3: 36c-38d. Al drie eenhede gee die name weer in die omgekeerde volgorde van die bron waaruit dit geneem is. Die eerste van hierdie drie eenhede is nie SondergutLukas nie en word dus nie by hierdie geleentheid bespreek nie. Die laaste twee eenhede is wel Sondergut-Lukas en verdien aandag. 'n Vergelyking tussen die name 
van hierdie twee eenhede met dié van die betrokke dele uit Genesis ontplooi soos volg:

: $24-32=$ Tera

: 23-29 = Nahor

: $21-23$ = Serug

: $19-21=$ Rehu

: $17-19=$ Peleg

$: 15-17=$ Heber

: $13-15=$ Sala

: 12-13 = Kenan

: $10-13=$ Arpagsad

$: 10-11=$ Sem

Genesis 5: 1-32

$: 32=$ Sem

$: 29-32 \quad=$ Noag

$:$ 25-31 = Lameg

$: 21.27=$ Metusalag

$: 18-24=$ Henog

$: 15-20 \quad=$ Jared

$: 12-17 \quad=$ Mahalalel

: 9-14= Kenan

: 6-11= Enos

: $3-8=$ Set

$: 1-5 \quad=$ Adam

$: 1=$ God

$$
\begin{aligned}
: 34 \mathrm{~d} & =\text { Tera } \\
\mathrm{e} & =\text { Nahor } \\
: 35 \mathrm{a} & =\text { Serug } \\
\mathrm{b} & =\text { Rehu } \\
\mathrm{c} & =\text { Peleg } \\
\mathrm{d} & =\text { Heber } \\
\mathrm{e} & =\text { Sala } \\
: 36 \mathrm{a} & =\text { Kenan } \\
\mathrm{b} & =\text { Arpagsad } \\
\mathrm{c} & =\text { Sem }
\end{aligned}
$$

Lukas 3: 36c-38d

$$
\begin{aligned}
: 36 \mathrm{c} & =\text { Sem } \\
\mathrm{d} & =\text { Noag } \\
\mathrm{e} & =\text { Lameg } \\
: 37 \mathrm{a} & =\text { Metusalag } \\
\mathrm{b} & =\text { Henog } \\
\mathrm{c} & =\text { Jared } \\
\mathrm{d} & =\text { Mahalalel } \\
\mathrm{e} & =\text { Kenan } \\
: 38 \mathrm{a} & =\text { Enos } \\
\mathrm{b} & =\text { Set } \\
\mathrm{c} & =\text { Adam } \\
\mathrm{d} & =\text { God }
\end{aligned}
$$

Dit wil hieruit voorkom asof die outeur vir hierdie Sondergut-Lukasmateriaal beslis die Septuaginta-tekste van Genesis 5 en 11 fisies voor hom oop kon gehad het. Hy beweeg terug in sy manuskrip tot by die einde van die genealogie in Genesis 11 en noem dan die name van onder af regdeur tot by die begin van die register. Hierna blaai hy gewoon na Genesis 5 en herhaal presies dieselfde prosedure. Hy tel die naam van Sem op tussen die seuns van Noag en beweeg dan hiervandaan terug na die begin van die register waar daar staan: 'Op die dag het God vir Adam gemaak; 
volgens die "beeld" van God het Hy hom gemaak'.

Vir Lukas moes die genealogieë van Genesis 5 en 11 die oudstes gewees het, want dit voer hom terug na die ontstaan van die mens. Die opskrif van die genealogie in Genesis 5 spreek dan ook in hierdie verband boekdele: 'Hierdie is die boek van die geslagte van die mense ....'

Maar hoe kan ons seker wees dat Lukas vir hierdie deel van sy genealogie spesifiek die Septuaginta en nie die Hebreeuse tekste wat aan ons bekend is, gebruik het nie? Daar is tog wel 'n bewys wat aangevoer sou kon word. In die Hebreeus ontbreek die Septuaginta-naam Kainam duidelik in Genesis 11. Deurdat Lukas dus hierdie naam opneem, moet daar beslis ten gunste van die Septuaginta, bó die Hebreeuse tekste wat aan ons bekend is, gekies word - tensy hy moontlik 'n ander Hebreeuse tekstradisie gevolg het wat vir ons vandag onbekend is, maar wat dieselfde Vorlage as die Septuaginta deel. Dit verander egter niks aan die feit dat die naam Kainàm nie in ons bestaande Hebreeuse tekstradisie te vind is nie.

Ook Plummer (1964: 104) wys daarop dat hierdie naam nie in enige van die Hebreeuse manuskripte voorkom nie, of selfs in enige ander vertaling van die Hebreeus nie.

Dit wil dus voorkom asof die laaste deel van die Lukaanse genealogie van direkte Septuaginta-invloed getuig. Tog skryf Lukas hier nie slaafs die Ou Testament-genealogieë oor nie, maar gebruik slegs die name daaruit. Verder las hy dit aanmekaar en bied hy dit aan in die raamwerk van sy eie interpretasie hiervan. Soms gebruik Lukas sekere elemente uit die inhoud van die Ou-Testamentiese materiaal en bied dit in sy eie vorm aan (soos hier by die genealogie). Ander kere gebruik hy egter weer die vorm van die Ou-Testamentiese materiaal (soos by die kinderloosheidsmotief) en klee dit dan in met sy eie inhoud.

Die feit dat Lukas telkens aan die einde van die genealogie van sy bronne hierbo begin en opwaarts beweeg na die begin daarvan, kan moontlik as 'n sleutel tot die ontsluiting van die bron(ne) by die eerste helfte van die Lukaanse genealogie dien. Hierdie bron(ne) lê waarskynlik tussen die Kronistiese geskrifte en die einde van die huidige Septuaginta-bundel (Bel en die draak). In 'n ondersoek na die bron(ne) van die eerste helfte (re : Lukas-genealogie) sal daar egter versigtig te werk gegaan moet word omdat hierdie materiaal nie Sondengut-Lukas is nie en daarom waarskynlik nie direk deur die Septuaginta beinvloed is nie.

\section{AFSLUTTING}

Deur gebruik te maak van verskillende motiewe uit die Ou Testament, blyk dit duidelik dat die skrywer die vorm van hierdie motiewe kon gebruik, dit dan vul met 
nuwe karakters en omstandighede en dit hierna in 'n 'vars geredigeerde' weergawe aanbied. Dit is veral opvallend dat daar so baie frases en sinne in die motiewe teenwoordig is, wat grootliks (of selfs identies) ooreenstem met die bewoording van die Septuaginta. ' $n$ Moontlike verklaring hiervoor is dat die skrywer miskien skriftelike dokumente van die Septuaginta as selfstandige bronne gebruik het.

In die lig hiervan sal daar dalk weer na die bronne van die Evangelieskrywers gekyk moet word. Behoort die Septuaginta-dokumente nie ook langs Markus en Q as selfstandige bronne van die skrywer van die Lukasevangelie genoem te word nie, en selfs op dieselfde wyse hanteer te word binne die Sondengut-materiaal nie?

Een van die grootste redes vir die voorkoms van Septuaginta-stof in die Lukasevangelie, en dan veral in die Sondergut-Lukas, sou dus gevind kon word in die feit dat die Griekse vertalings van die Hebreeuse Ou-Testamentiese dokumente as selfstandige bron(ne) deur Lukas gebruik kon gewees het vir die kompilasie van hierdie materiaal.

\section{Literatuurverwysings}

BROWN, RE 1977. The birth of the Messiah: $A$ commentary on the infancy narratives in Matthew and Luke. New York: Doubleday.

CADBURY, HJ [1920] 1969. The style and literary method of Luke. New York: Kraus Reprint. (Harvard Theological Studies VI.)

DU PLESSIS, IJ 1980. Die Evangelie volgens Lukas: Inleiding en teologie, in Du Toit, AB (red), Handleiding by die Nuwe Testament, IV, 156-201. Pretoria: NG Kerkboekhandel.

GOULDER, MD \& SANDERSON, ML 1957. St Luke's genesis. JThS 8, 12-30.

HOLTZ, T 1968. Untersuchungen über die alttestamentliche Zitate bei Lukas.

Berlin: Akademie Verlag.

KURZ, WS 1984. Luke 3: 23-38 and Greco-Roman and Biblical genealogies, in Talbert, CH (ed), Luke-Acts: Perspectives from the Society of Biblical Literature Seminar, 169-187. New York: Crossroad.

MARSHALL, IH 1978. The Gospel of Luke. Exeter: Paternoster.

MULDER, H 1948. De eerste hoofdstukken van het Evangelie naar Lukas in hun strukturele samenhang. Delft: Meinema.

PLUMMER, A 1964. The Gospel according to St Luke. Edinburgh: T \& T Clark. (ICC.)

RAHLFS, A 1935. Septuaginta, Vol I \& II. Stuttgart: Deutsche Bibelstiftung.

RESE, M 1965. Alttestamentliche Motive in der Christologie des Lukas. DTh-Diss, Rheinischen Friedrich-Wilhelms Universität, Bonn. 
RUDDICK, CT 1970. Birth narratives in Genesis and Luke. NT 12, 343-348.

SILVA, M 1976. Semantic borrowing in the New Testament. NTS 22, 104-110.

STEYN, GJ 1987a. Die eksegetisering van Ou Testamentiese stof in die Nuwe Testament: Enkele probleme en 'n moontlike model. Theologia Evangelica 20/3, 29-37.

STEYN, GJ 1987b. Septuaginta-invloed op die taal en styl van die Lukasevangelie. MA-verhandeling, Departement Grieks, Universiteit van Pretoria.

SWETE, HB 1914. An introduction to the Old Testament in Greek. Cambridge: Cambridge University Press.

TALBERT, CH 1984. Promise and fulfillment in Lukan theology, in Talbert, CH (ed), Luke-acts: New Perspectives from the Society of Biblical Literature Seminar, 91-103. New York: Crossroad. 